\title{
Why small and medium chemical companies continue to pose severe environmental risks in rural China
}

\author{
Guizhen He ${ }^{a}$, Lei Zhang ${ }^{b}$, Arthur P.J. Mol ${ }^{c}$, Tieyu Wang ${ }^{a}$, Yonglong Lu ${ }^{\mathrm{a}, *}$ \\ a State Key Laboratory of Urban and Regional Ecology, Research Centre for Eco-Environmental Sciences, Chinese Academy of Sciences, Shuangqing Road 18, \\ Beijing 100085, China \\ ${ }^{\mathrm{b}}$ School of Environment and Natural Resources, Renmin University of China, Beijing 100872, China \\ ${ }^{\mathrm{c}}$ Environmental Policy Group, Wageningen University, Hollandseweg 1, $6706 \mathrm{KN}$ Wageningen, The Netherlands
}

\section{A R T I C L E I N F O}

\section{Article history:}

Received 16 September 2013

Received in revised form

22 October 2013

Accepted 31 October 2013

\section{Keywords:}

Chemical industry

Small and medium-sized enterprises

Environmental risk management

Rural China

\begin{abstract}
A B S T R A C T
In China, rural chemical SMEs are often believed to still largely operate below the sustainability radar. This paper investigates to what extent and how chemical SMEs are already experiencing pressure to improve their environmental performance, using an in-depth case study in Jasmine County, Hebei province. The results show that local residents had rather low trust in the environmental improvement promises made by the enterprises and the local government, and disagreed with the proposed improvement plans. Although the power of local residents to influence decision making remained limited, the chemical SMEs started to feel increasing pressures to clean up their business, from governments, local communities and civil society, and international value chain stakeholders. Notwithstanding these mounting pressures chemical SME's environmental behavior and performance has not changed radically for the better. The strong economic ties between local county governments and chemical SMEs continue to be a major barrier for stringent environmental regulation.
\end{abstract}

(c) 2013 Elsevier Ltd. All rights reserved.

\section{Introduction}

Since the early 1980s, rural industries originally referred to as Township \& Village Enterprises (TVEs) and later relabeled small and medium-sized enterprises (SMEs), have been a significant engine of China's economic transition. The promulgation of the 2002 Law of China on the Promotion of Small and Medium-sized Enterprises caused a new acceleration of SME development. ${ }^{1}$ In 2009, China had registered 43 million SMEs, together responsible for $58.5 \%$ of the national GDP, half of China's tax revenues, $68 \%$ of China's exports, and nearly $80 \%$ of the job opportunities in cities and towns (Xinhua, 2012).

However, the environmental costs of China's rural industrialization are enormous (Wang et al., 2008). Rural industries have been and still are notorious for their air and water pollution, for their inefficient use and waste of natural resources, for the destruction of

\footnotetext{
* Corresponding author.

E-mail addresses: gzhe@rcees.ac.cn (G. He), lei.zhang@wur.nl (L. Zhang), arthur. mol@wur.nl (A.P.J. Mol), wangty@rcees.ac.cn (T. Wang), yllu@rcees.ac.cn (Y. Lu).

1 In China, industrial companies with less than 1000 employees and an annual income of less than 400 million yuan (63 million U.S. dollars) qualify as SMEs; companies with less than 20 employees and less than 3 million yuan in annual income are considered to be "micro-companies", according to Document No.300 MIIT in 2011.
}

the ecological environment and for damaging human health (Zhang, 2002). Many studies ascribe the poor environmental performance of SMEs to the sheer number and dispersement, the substandard production technology, their poor operation and management systems and routines, the shortage of finances, the lack of environmental awareness, and last but not the least: the strong local government-SME alliance (Guo and Zheng, 2012; Kostka and Mol, 2013). Rural SMEs continue to be notorious polluters, regardless of specific efforts and campaigns, such as the massive 1997 SME closure campaigns (Xu et al., 2001). Among these rural SMEs, chemical and petro-chemical companies are among the most polluting and also blamed for causing so-called "cancer villages" in China (Sun, 2009). ${ }^{2}$

Following increasing numbers of chemical pollution accidents chemical risk management has moved high on China's policy agendas and chemical companies experience increasing state, public and value chain pressure to improve their environmental performance (He et al., 2011, 2012a). While there is growing evidence of mounting pressure on chemical companies to clean up

\footnotetext{
2 By the end of 2010 the total number of petrochemical and chemical plants in China reached nearly 96,000, of which 60,000 are small scale ones. Almost half of the 1800 pesticide production enterprises were SMEs, according to the National Bureau of Statistics of China (2011).
} 
their business in China, this is not necessarily so for chemical SMEs in rural China. Existing studies on environmental performances of chemical companies rarely distinguish between rural SMEs and urban, transnational companies (Grasa et al., 2002; He et al., 2012b; Huang et al., 2013; Zhang et al., 2013). But if a distinction is made, small rural chemical SMEs are often believed to still largely operate below the sustainability radar in China, because: 1) unlike the larger companies they are hardly visible in the national and international media; 2) they are less internationally integrated; 3) they are less subject to stringent governmental regulation and enforcement, also because local governments have key (financial, economic, political) interests in maintaining these companies in operation within their jurisdiction; 4) they are less confronted with a well-informed, environmentally aware, and well-resourced Chinese middle class, as rural neighboring residents lack (access to) information, knowledge, legal aid, and non-governmental organizations (NGOs).

But the "environmental frontier" in China is far from static and those practices and organization that could function below the sustainability radar just a few years ago might very soon become visible for increasingly independent state environmental agencies, a better informed civil society and growing international interdependencies. This paper aims to investigate to what extent and how chemical SMEs in rural China are already experiencing pressure to improve their environmental performance, using an indepth case study in Jasmine County in Hebei province. The next section presents the analytical framework and methodology followed by an overview of environment pollution and performance of the case study chemical SMEs. Sections 4-6 analyze the legal and administrative interventions on, the interactions of civil society with, and the international value chain impact on SME environmental performance, respectively. Section 7 concludes the paper with suggestions for the future of rural SME risk management in China.

\section{Changing chemical risk politics in rural China: framework and methodology}

\subsection{Research framework}

In rural China, local leaders strongly facilitated the establishment of new SMEs as these factories were expected to drive local economic development, played a main role in fulfilling targets of local leaders, and local leaders more than incidentally had a financial stake in local companies (OCED, 2006). Local governments tend to form close relationships with polluting enterprises as an "alignment of interests" aiming to speeding up the economic growth and taking environmental protection as a secondary objective (Guo and Zheng, 2012). Rural SMEs had particularly strong incentives to cultivate good relationship with bureaucrats, because they had difficulties in obtaining preferential treatment from the central government; a consequence of the 'liability of smallness' and lack of legitimacy (Wu and Leung, 2005). This intricate relationship between local governments and polluting companies had consequences for environmental policy-making and implementation. Although in principle firms that failed to comply with environmental regulations risked incurring noncompliance penalties and revoking of their operating permits (Weng and Lin, 2011; Smallbone and Welter, 2001), in the practice of rural China application remains limited. Especially in the case of pollution from "key protected firms" local enforcement was powerless due to dependence on the local government (Wang et al., 2008; Van Rooij and Lo, 2010; Stevens et al., 2013), and the career paths of Environmental Protection Bureau (EPB) leaders (Kostka, 2013; Liu et al., 2012). Pressures from higher level governments and agencies, the public, and international economic relations, put pressure on the lax chemical risk management through a closed and protective relationship of local governments and SMEs.

Faced with severe chemical pollution and increasing public pressure, China's leadership developed a large number of policy initiatives and ambitious investments (Liu et al., 2012). A series of laws, regulations, standards, and actions on chemical risk management has been promulgated and the central government has started to improve enforcement of its environmental laws and regulations (MEP, 2012, 2013; Wang et al., 2012). The number of environmental inspections by national environmental and other agencies has increased to ensure supervision by local EPBs and compliance and risk management by local companies, especially SMEs. The national environmental monitoring system and inspection and enforcement institutions have been gradually improved to ensure a better surveillance of the compliance of environmental regulations by Chinese and foreign SMEs (Stevens et al., 2013). A new emerging Chinese middle-class started to articulate their environmental interests in recent years, as displayed by antipollution protests which confront local governments and enterprises with their environmental abuses (Göbel and Ong, 2012; Kennedy, 2012; Yang and Calhoun, 2007). Chemical companies in China have also become subject to increasing civil society scrutiny, as increasing numbers of NGOs, media, and citizens and residents living adjacent to these chemical facilities now complain, report and protest on the risks of these facilities, especially following a number of very visible incidences (Lee, 2008; Liu et al., 2010; Qi et al., 2012; Tang and Tang, 2012). But, rural and low-income people found it still difficult to defend their rights in environmental disputes because they often lack similar means, capacity and freedoms as the urban middle class. Some of them may be bold and resourced to seek material compensation from authorities or companies, but most of them not. In the countryside social networks, microblogs and knowledge and information infrastructures are difficult to access and poorly developed (Dong, 2012). However, better access to mobile phones and the Internet might enable rural population to learn from urban developments, to share, exchange and disseminate local information, and to coordinate movements and protests more effectively (Klein, 2011).

In addition, international linkages of chemical companies-e.g. by being part of a transnational company and/or through value chains linkages with global markets-have triggered the introduction of voluntary standards, global environmental management and corporate social responsibility systems, sustainability reporting initiatives, and advanced product quality programs, all contributing to improved environmental performance of Chinese chemical production facilities (Darnall et al., 2009; He and Yang, 2012; Mol, 2011; Zadek et al., 2012). In case of severe chemical risks, international corporate buyers and suppliers are more likely to respond by canceling purchasing or selling agreements, stopping delivery of an input, or requesting environmentally sound substitutes (Zadek et al., 2012; Henriques and Sadorsky, 1999). While the domestic value chain pressure on Chinese chemical SMEs is not yet emerging, Chinese SMEs are raising the bar to meet international standards of sustainability and responsibility as part of their strategy of internationalization and moving higher up the value chain.

In line with developments in OECD countries, a transition from state-dominated environmental regulation to more participatory environmental governance can be observed also in China during the past decade (Mol and Carter, 2006). The idea of environmental governance would mean the deviation from a model where the close ties between the local government and chemical SMEs is decisive on environmental reform of the latter, towards a model where three types of the actors are involved in chemical industry environmental management in rural China (see Fig. 1). Hence, apart from 


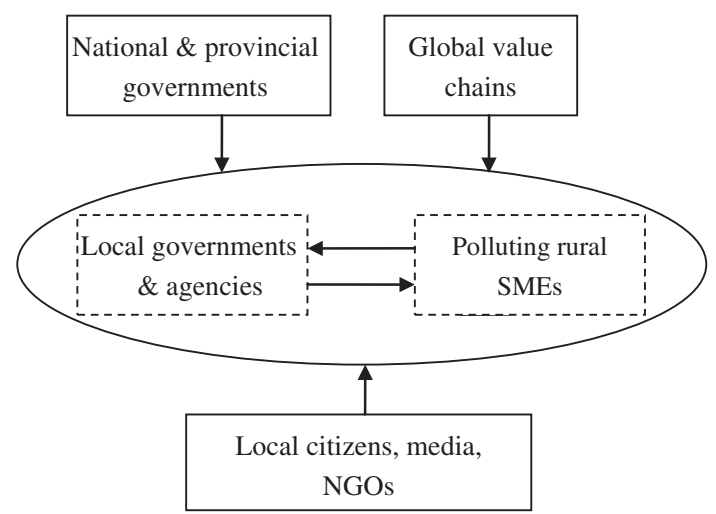

Fig. 1. Analytical framework to study the chemical risk management of SMEs in rural China.

investigating the close alliance between local government and chemical SMEs, also influences from other stakeholders were studied.

\subsection{Data collection and analysis}

Jasmine County (220,000 inhabitants) was selected to understand changing rural chemical risk politics. It is located $180 \mathrm{~km}$ away from Beijing, in the northwest of Zhang Jia Kou (ZJK) city in Hebei province. Jasmine County houses KD Pesticide and Chemical Corporation, one of the four pillar industries, which contributed $14 \%$ to the county's gross industrial output value in 2011. Jasmine County KD has three production facilities and one import and export company and employed around 900 workers from its nearby villages in 2011.

Several data collection methods were conducted. Grey governmental and company reports and (social) media reports were collected and analyzed over the period last decade. In addition, 11 indepth face-to-face interviews were conducted in 2012 with local governmental officials, managers of the chemical plants and village leaders. Finally, five out of 19 villages (54,000 inhabitants) around the three factories were chosen to survey face-to-face 550 randomly selected residents on their complaints, perceptions, attitudes and trust related to KD environmental and health performance in May 2012. From this survey, 523 (95\%) valid responses were obtained, of which $28 \%$ worked in one of the pesticide plants. About $50 \%$ of the respondents resided at less than $500 \mathrm{~m}$ from one of the plants. The majority of the respondents (71\%) were between 30 and 50 years old, and most (over 60\%) received at least junior middle school education. Annual family income of $70 \%$ ranged between 10,000 and 40,000 yuan. A very small minority was member of Communist Party of China ( $<6 \%$ ). All data were analyzed with SPSS 17.0.

\section{Environment pollution and performance of chemical SMEs}

KD evolved from a county level state-owned pesticide plant that was created in 1989. After a major ownership restructuring in 2002, KD was formed as a private shareholding chemical corporation, specialized in the production of active ingredients of insecticides, fungicides, herbicides, and plant growth regulators, and of fine chemicals. Over $90 \%$ of its products are exported to major transnational corporations, such as BASF and Makhteshim Agan Industries Ltd. In 2012, Huapont Pharm Co. Ltd acquired one of the production plants of KD and became a major shareholder. Tables 1 and 2 provide information on the three plants, the raw materials/chemicals used, the chemicals produced and their pollutant emissions. Many of the raw materials, produced products and emissions from these three plants belong to the category of dangerous and hazardous chemicals.

Ever since the operation of the first pesticide plant in 1989, highly toxic wastewater, solid waste and air pollutants have been discharged without any treatment and control measures, causing serious damage to the surrounding environment and local population. Over $78 \%$ of the survey respondents rated the local environmental quality before the chemical plants were constructed as "good", while nearly $85 \%$ rated the local environmental quality after construction as "bad" (on a three-point scale of "good", "in between", "bad"). The survey results indicated that air pollution was considered by far the most serious problem, followed by crop and vegetable damage, water pollution, soil pollution and noise pollution (Fig. 2). The growth of grains and vegetables has been affected and those grown close to the factory hardly survive. About $65 \%$ of the respondents do not trust local crops, vegetables, and drinking water quality. Over $75 \%$ of the respondents complain about health problems due to long-term environmental pollution and over $67 \%$ relate the increasing occurrence of cancer in the villages to the factories. Chi-square tests showed that there were significant differences on all these perceptions between respondents living close to and far away from chemical plants ( $\chi 2=109.79$, $p<0.001$ ), and also between the respondents working and notworking in KD chemical plants $(\chi 2=98.03, p<0.01)$.

According to interviews with plant environmental managers, all three plants have recently adopted advanced technologies that minimized negative environmental effects. Recently some engineering measures were taken, including protective cofferdam, absorption devices for gas leaking, the construction of emergency discharge pools for wastewater, and warning systems for liquid and gas leakages. A waste landfill was shared by the three plants and toxic waste was contracted to a specialized collection and disposal company. The managers denied that the three plants should be held responsible for any local environmental problems and argued that all plants met the national emission standards. They also claimed to have informed local residents on plant environmental performances and never received complaints from local residents. The only exception formed $\mathrm{LH}$ who admitted compensation payment to local farmers for causing damage to their crops, and a fine of 100,000 RMB (16,100 US dollars) to the county EPB for a water pollution accident in 2011.

\section{Governmental control: legal and administrative interventions}

Among the factors that drive SMEs to improve environmental performances, national, provincial and local governments have

Table 1

Basic information of three chemical plants of KD Corporation.

\begin{tabular}{|c|c|c|c|c|c|c|c|}
\hline Name & $\begin{array}{l}\text { No. of } \\
\text { employees }\end{array}$ & Scale & Production process & Main dangerous raw materials & $\begin{array}{l}\text { Amount of raw } \\
\text { materials }(\mathrm{t} / \mathrm{a})\end{array}$ & Products & $\begin{array}{l}\text { Total output } \\
\text { in } 2011 \text { (ton) }\end{array}$ \\
\hline $\mathrm{LH}$ & 400 & Medium & Intermittent production & $\begin{array}{l}15 \text { types, e.g. methanol, } \\
\text { methylbenzene, liquid ammonia }\end{array}$ & 5260 & Picloram, Clopyralid, Fluroxypyr & 2000 \\
\hline HY & 450 & Medium & Intermittent production & $\begin{array}{l}21 \text { types, e.g. Sodium cyanide, } \\
\text { DMB, Crotonaldehyde }\end{array}$ & 21,400 & Metamitron, Clethodim & 1854 \\
\hline$X Y$ & 130 & Small & Intermittent production & $\begin{array}{l}7 \text { types, e.g. polyoxymethylene, } \\
\text { methylbenzene }\end{array}$ & 653 & Metazachlor, Carbetamide & 180 \\
\hline
\end{tabular}


Table 2

Pollution emissions from three production plants in full operation (2011).

\begin{tabular}{|c|c|c|c|c|c|}
\hline Type & & Pollutants & Generation amount in HY & Generation amount in $\mathrm{XY}$ & Generation amount in $\mathrm{LH}$ \\
\hline \multirow[t]{12}{*}{ Waste gas } & \multirow[t]{5}{*}{ Boiler flue gas } & Volume $\left(10,000 \mathrm{~m}^{3} / \mathrm{a}\right)$ & 3885 & 5123.5 & 13320 \\
\hline & & Smoke and dust (t/a) & 3.99 & 1.87 & 7.96 \\
\hline & & $\mathrm{SO}_{2}(\mathrm{t} / \mathrm{a})$ & 22.8 & 10.71 & 56.78 \\
\hline & & $\mathrm{NO}_{\mathrm{x}}(\mathrm{t} / \mathrm{a})$ & & & 14.43 \\
\hline & & $\mathrm{NH}_{3}(\mathrm{t} / \mathrm{a})$ & & & 0.07 \\
\hline & \multirow[t]{7}{*}{ Process exhaust } & Volume $\left(10,000 \mathrm{~m}^{3} / \mathrm{a}\right)$ & 13019.84 & & 6480 \\
\hline & & Methanol (t/a) & 2.0484 & & 0.012 \\
\hline & & Dimethylbenzene (t/a) & 5.872 & & \\
\hline & & Methylbenzene (t/a) & 0.0855 & 1.06 & 0.757 \\
\hline & & $\mathrm{HCl}(\mathrm{t} / \mathrm{a})$ & & 0.4 & \\
\hline & & Formaldehyde (t/a) & & 0.51 & \\
\hline & & 2-Methoxyethanol (t/a) & & & 0.765 \\
\hline \multirow[t]{4}{*}{ Wastewater } & \multirow[t]{4}{*}{ Discharge outlet } & Volume of wastewater $\left(\mathrm{m}^{3} / \mathrm{a}\right)$ & 22831 & 810 & 11730 \\
\hline & & $\operatorname{coD}(t / a)$ & 1.14 & 0 & 1.2 \\
\hline & & $\mathrm{BOD}_{5}(\mathrm{t} / \mathrm{a})$ & 0.41 & & \\
\hline & & Ammonia nitrogen ( $t / a)$ & & & 0.16 \\
\hline \multirow[t]{3}{*}{ Solid waste } & Waste fluid (t/a) & 10620 & & 1706 & \\
\hline & General solid waste $(\mathrm{t} / \mathrm{a})$ & 269.6 & 396 & 2613 & \\
\hline & Dangerous solid waste (t/a) & 525 & 24.2 & 573.6 & \\
\hline
\end{tabular}

everywhere been a major force (Darnall et al., 2009; Smallbone and Welter, 2001). The case of KD illustrates both the significant efforts of national governmental agencies to regulate pesticides companies, but also the growing involvement of local governmental agencies to intensify enforcement and control of these regulations, with ambivalent successes.

\subsection{National regulations and interventions}

In China, the supervision, management and control of pesticides are allocated to different agencies. The legal system for SMEs involved in pesticides handling includes laws, regulations, ordinances, and standards (Lu et al., 2007; Wang et al., 2005). Till March 2013, 38 national laws, 48 State Council regulations, 196 national government department ordinances, and 324 national and industrial pesticide standards had been promulgated, targeting licensing/classification, production, storage/packaging, transportation, trade/import/export, use, disposal, and supervision (Table 3). About half of the laws and regulations target the licensing and production of pesticides. The Ministry of Environmental Protection (MEP), the State Administration of Work Safety (SAWS), and the General Administration of Quality Supervision, Inspection and Quarantine (AQSIQ) are the most important governmental departments for issuing departmental regulations on pesticides (Fig. 3). Broadly speaking, these laws and regulations impose obligations to make less comprehensive and more specific products in a safer, cleaner, more efficient way, by using less hazardous raw materials, less energy and water, and producing fewer toxic wastes (McElwee, 2011).

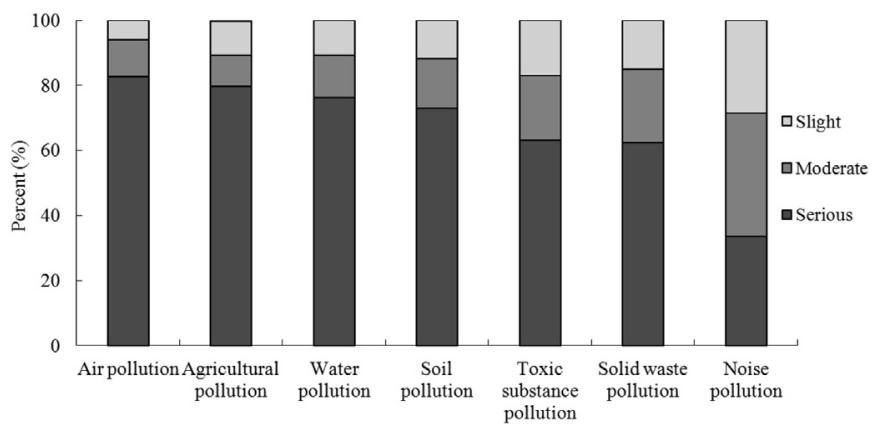

Fig. 2. The respondents' assessment on the local environmental pollution.
Table 4 shows the basic functions of 18 ministries and commissions involved in pesticides management and supervision. Whereas the Ministry of Agriculture (MoA) is mainly responsible for registration, storage safety and pesticides application, industrial pollution prevention and control of pesticides is the responsibility of MEP. Given the significant environmental and health impact caused by KD, the two larger plants of KD have been listed by the MEP as key national enterprises for extra monitoring and supervision on wastewater and dangerous solid waste discharge since 2009. This means that provincial, municipal and county EPBs (should) have strongly focused on regulating these two plants (see below). In the Pollution Prevention and Control Plan of Haihe Watershed (2006-2010), issued by MEP, KD was required to build and operate a wastewater treatment station. As Huapont Pharm Co., Ltd, a major shareholder of $\mathrm{LH}$, applied for being listed in the stock market in 2010, LH was assessed by MEP on its environmental compliance according to Notice on the Inspection and Verification of Environmental Protection of the Corporations Applying for Listing and the Listed Corporations Applying for Refinancing, enacted by the former State Environmental Protection Administration (now MEP) in 2003. LH obtained approval from the MEP and hence could be listed on the Chinese stock market. The SAWS plays a key function for safety supervision and inspection of the chemical facilities. Emergency management of the chemical plant is controlled by SAWS and MEP.

\subsection{Changing roles of local governmental agencies}

Over the past decades the Chinese government has defined main responsibility of environmental law and regulation enforcement to the local EPBs, and also increased the number of environmental inspection agencies and environmental inspectors to strengthen the local governments. The local governments and their subordinate agencies have also taken several measures and actions to supervise the operation and environmental risk management of the four chemical facilities (Table 5). In general, most provincial and prefectural/city agencies play indirect roles, but the county government and its divisions have more direct roles in environmental enforcement, inspection and supervision. The provincial, city and county EPBs have been responsible for supervising the pollution prevention and control of the national key polluting industries, such as KD. However, for a long time their monitoring in the case of $\mathrm{KD}$ industries only focused on routine pollution indicators, while 
Table 3

Pesticide-relevant laws and regulations.

\begin{tabular}{|c|c|c|c|c|c|c|c|c|c|}
\hline & Licensing & Production & Storage & Transportation & Trade, export \& import & Use & Disposal & Supervision & Total \\
\hline Laws & 8 & 9 & 2 & 2 & 6 & 5 & 8 & 2 & 38 \\
\hline Regulations & 11 & 10 & 4 & 5 & 8 & 4 & 7 & 2 & 48 \\
\hline Ordinances & 49 & 36 & 7 & 31 & 29 & 11 & 12 & 40 & 196 \\
\hline Standards & 11 & 269 & 4 & 5 & 2 & 21 & 6 & 13 & 324 \\
\hline International conventions & 1 & 4 & & 1 & 2 & 2 & & 2 & 13 \\
\hline
\end{tabular}

Sources: websites of the State Council and national governmental agencies

hardly paying attention to special (and more toxic) pollutants from these chemical plants. Hence, they were not in a position to identify the causality between pollution levels and the observed and claimed environmental and health effects.

The three chemical plants indeed felt increasing pressure over the past decade from local governments and their agencies, which forced them to take actions to improve industrial environmental management. But environmental protection did not become a company priority. Three plants did conduct EIAs only in 2010 and 2011, although such EIAs should have been done before the plants were constructed according to the Chinese EIA Law. Only in 2009, after 20 years of unbridled pollution discharge, the three plants finally were ordered to improve their environmental management and to construct waste water treatment stations. Although LH and HY constructed their wastewater treatment stations and installed online monitoring on $\mathrm{COD}$ and $\mathrm{NH}_{3}-\mathrm{N}$ and an accident alarm system, the environmental maintenance and operation of these facilities remained problematic. Even under increasingly stringent supervision, the provincial EPB found in 2011 that XY dumped toxic waste illegally in Shanxi, but the company did not face any punishment.

Local governmental actions and enhanced supervision were expected to ensure a better environmental compliance of these SMEs. However, KD was a local economic pillar firm and a large taxpayer, and the director of KD had close personal connections with county governmental officials. Hence, in practice the county EPB applied and enforced lower environmental protection standards, according to interviewed workers and villagers. In the case of the three KD plants implementation of environmental laws and policies continued to remain a problem. When confronted with serious pollution problems from "key protected plants", local enforcing EPBs proved powerless due to their dependence on local government leaders.

But this might be changing in the near future. KD chemical industry has been one of the four key industries of Jasmine County

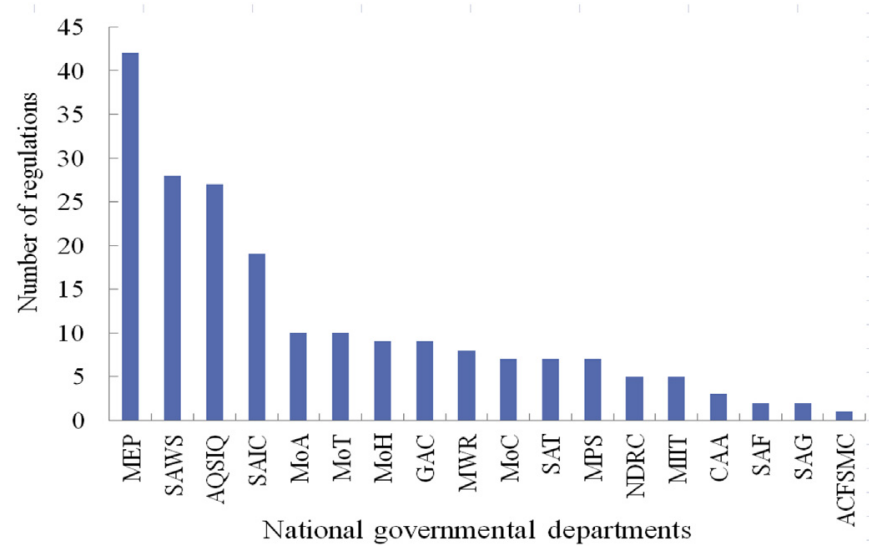

Fig. 3. Departmental pesticides regulations promulgated by different Chinese ministries and commissions till March 2013 (see abbreviations in Table 4). over the last decade, but this ended with the local 12th Five-Year Plan of Economic and Social Development, promulgated by Jasmine County government in the end of 2011. In this new Plan priority is given to six other industrial sectors, all with low pollution, an advanced technological component, and high added-value, among which agricultural product processing and service industries. This "downgrading" of the importance of chemical industries will make their "protection" by local government leaders less strong, and opens up possibilities for a more stringent control and enforcement of local EPBs. However, making environmental protection a priority of the local government in the long term would depend on what kind of incentive system would be introduced by the upper level government regarding evaluation on the (environmental) performance of the local government and local leaders.

\section{Civil society and SME pollution}

The likelihood of more stringent control and enforcement of KD factories is enhanced by continuing pressure from local citizens. Here we report on the knowledge of local citizens, their complaints and protests to the county government and EPB, and their (limited) engagements with media representatives and the Internet.

\subsection{Citizen's knowledge, information and assessment}

What do local citizens know and from whom do they get their (reliable) information? Currently, more than 93\% of the respondents attribute the poor local environmental conditions to pollution discharges of nearby chemical plants and over $84 \%$ of the respondents knew about specific environmental accidents of the chemical plants. But many respondents have little specific knowledge or information on chemical pollution: about $28 \%$ of the respondents knew the destination of the plants' wastewater discharges and $21 \%$ of the respondents knew where chemical solid waste ends up. Residents' knowledge on EPB actions towards KD polluting plants is also limited. About $22 \%$ of the respondents knew that local EPB took some measures and actions after severe pollution incidents, including fining the companies and temporarily stopping production. A quarter of the respondents knew that the chemical plants constructed wastewater treatment stations. Knowledge of residents on chemical plants, their pollution and the measures being taken were obtained mainly from relatives and friends (over 38\%), and self-experience (over 28\%) (Fig. 4). The county EPB and government were hardly considered important information sources. Employees of the plants considered information from chemical plant managers particularly important, especially regarding chemical production activities, work safety, pollution prevention measures, and chemical hazards and human health impacts.

Not all sources of information are equally trusted by local citizens. Fig. 5 illustrates that the central government (61\%), scientists in universities and institutes (46\%), and relatives \& friends (46\%) were ranked as the most trustworthy sources of information with respect to pollution issues of the KD plants. Chemical plants and 
Table 4

National governmental ministries and commissions and their functions in chemicals management in China.

\begin{tabular}{|c|c|c|c|c|c|c|c|c|c|}
\hline Departments ${ }^{\mathrm{a}}$ & Licensing & Production & Storage & Transportation & Import/Export & Trade & Use & Disposal & Supervision \\
\hline ACFSMC & $\sqrt{ }$ & & & & & $\sqrt{ }$ & & & \\
\hline AQSIQ & $\sqrt{ }$ & $\sqrt{ }$ & & & $\sqrt{ }$ & $\sqrt{ }$ & & & $\sqrt{ }$ \\
\hline CAA & & & $\sqrt{ }$ & $\sqrt{ }$ & & & & & \\
\hline GAC & & & & & $\sqrt{ }$ & & & & \\
\hline MEP & $\sqrt{ }$ & $\sqrt{ }$ & $\sqrt{ }$ & $\sqrt{ }$ & $\sqrt{ }$ & $\sqrt{ }$ & $\sqrt{ }$ & $\sqrt{ }$ & $\sqrt{ }$ \\
\hline MoA & $\sqrt{ }$ & $\sqrt{ }$ & $\sqrt{ }$ & $\sqrt{ }$ & $\sqrt{ }$ & $\sqrt{ }$ & $\sqrt{ }$ & $\sqrt{ }$ & $\sqrt{ }$ \\
\hline MoC & $\sqrt{ }$ & & & $\sqrt{ }$ & $\sqrt{ }$ & $\sqrt{ }$ & $\sqrt{ }$ & $\sqrt{ }$ & $\sqrt{ }$ \\
\hline $\mathrm{MoH}$ & $\sqrt{ }$ & $\sqrt{ }$ & & & $\sqrt{ }$ & $\sqrt{ }$ & $\sqrt{ }$ & & $\sqrt{ }$ \\
\hline MoT & & & $\sqrt{ }$ & $\sqrt{ }$ & & & & & \\
\hline MWR & & $\sqrt{ }$ & & & & & & $\sqrt{ }$ & \\
\hline NDRC & $\sqrt{ }$ & & & & & & & & $\sqrt{ }$ \\
\hline MIIT & $\sqrt{ }$ & $\sqrt{ }$ & & & & & & & $\sqrt{ }$ \\
\hline MPS & & $\sqrt{ }$ & $\sqrt{ }$ & $\sqrt{ }$ & & $\sqrt{ }$ & $\sqrt{ }$ & & $\sqrt{ }$ \\
\hline SAIC & & & & & & & & & \\
\hline SAF & $\sqrt{ }$ & & & & & $\sqrt{ }$ & $\sqrt{ }$ & & \\
\hline SAG & $\sqrt{ }$ & & & & & & $\sqrt{ }$ & & \\
\hline SAT & & & & & & $\sqrt{ }$ & & & \\
\hline SAWS & $\sqrt{ }$ & $\sqrt{ }$ & $\sqrt{ }$ & $\sqrt{ }$ & & $\sqrt{ }$ & $\sqrt{ }$ & $\sqrt{ }$ & $\sqrt{ }$ \\
\hline
\end{tabular}

a ACFSMC, All China Federation of Supply and Marketing Cooperatives; AQSIQ, General Administration of Quality Supervision, Inspection and Quarantine; CAA, Civil

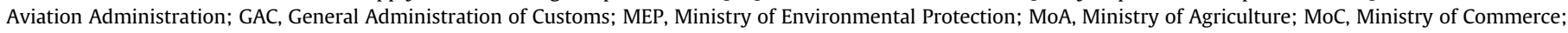

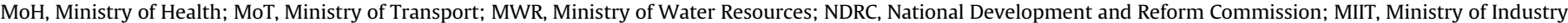

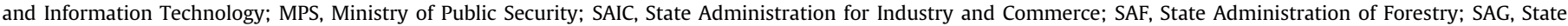
Administration of Grain; SAT, State Administration of Taxation; SAWS, State Administration of Work Safety.

local governments were both perceived as unreliable sources of information, illustrating that local citizens interpret both actors as having similar interests.

Three traditional dimensions of attitudes were assessed with 5point Likert scale, including the cognitive (How is your attitude towards building a chemical plant nearby your village?), emotional (How do you consider the risks of the chemical plant?), and behavioral (What is the likelihood that you will (re)locate far away from the chemical plant?) aspects (Fig. 6). The results indicated that more than $90 \%$ of the respondents opposed the construction of the chemical plants nearby their home, whilst $78 \%$ had major worries on chemical plant risks. In order to protect themselves and their families, over $76 \%$ would like to move to a more distant location from the chemical plants. Chi-square tests show a strong NIMBY effect: those living closer to the chemical plant indicate stronger opposition $(\chi 2=116.08, p<0.001)$, more worries $(\chi 2=111.06$ $p<0.001$ ), and more intentions to relocate $(\chi 2=90.80, p<0.01)$ than those living far from the plants. As expected, chemical plant employees are less opposed $(\chi 2=60.48, p<0.05)$ and less worried $(\chi 2=55.76, p<0.05)$ compared to non-employees. Our results contrast sharply with the EPB-organized surveys in the framework of EIAs of the three plants, in which $80-90 \%$ of the respondents agreed on the site selection of the plants and ventilated no pollution complaints. This puts these EIA reports in a different and doubtful light.

Most respondents (81\%) do not tolerate pollution risks, even when they come with economic benefits of the chemical industry. A risk-benefit balance showed that more than $55 \%$ of the respondents thought that local residents did not get any benefits from the chemical plants. Nearly $30 \%$ of the respondents mentioned job opportunities as a benefit. Air pollution (26\%), increase of cancer (24\%) and the crops damage (21\%) were the mostly mentioned costs (Fig. 7). Spearman correlations analysis showed that pollution toleration was less positive among high educated ( $p<0.01)$, high income $(p<0.05)$, and neighboring residents $(p<0.001)$. Party membership, gender, and age showed no significant differences in this regard. Nearly $53 \%$ of the respondents preferred the immediate shut down of the chemical factories, while $29 \%$ thought removal of the factories to a local industrial park could be a solution. This leaves little room for solving conflicts if the plants remain at their current sites.

\subsection{Local community action against SME pollution}

Given this information and assessment profile of Jasmine residents on KD industries it comes with little surprise that local residents have pressed the factories towards improvements. Efforts of local communities to press KD companies into environmental improvement failed to receive any support from the county government and upper level EPBs, until 2003 when a chemical leak from LH plant caused the death of crops and trees of nine nearby villages. The affected farmers organized a protest to the county government, which led the county government to order LH plant to temporarily stop production and to compensate 687 farmer households. Although the county EPB also stepped in, it did not take serious measures to improve plant environmental performance, except for imposing a fine. After this 2003 incident the chemical plants continued discharging pollutants until 2009 when the illegal pollution of the three KD plants was discovered and disclosed by the provincial EPB during one of the nationwide inspections on chemical plants following the Songhuajiang water pollution accident in 2005. After 20 years of almost unbridled pollution discharge, these plants finally received penalties and were ordered to improve their environmental management and to construct waste water treatment systems.

Local citizens are not just passive recipients of environmental pollution and risks of KD factories. Over $72 \%$ of the respondents have participated in complaints about pollution caused by the chemical plants. Around $55 \%$ of these complainants received at least once economic compensation, of which some were retaliated by the local government. But quite often complainants were told to go home to wait on the verdict, but in the end never received a response. Village leaders were supposed to negotiate with the chemical industry on compensation for damages on crops. However, most of the respondents did not know of such negotiations and never got such compensation. More than $80 \%$ of the respondents confirmed and complained about that the local EPB and the three plants did not communicate with them after pollution accidents. While being asked about their willingness to negotiate on compensation with the chemical plants, $65 \%$ of them would like to participate in such negotiations, but $35 \%$ thought such negotiations "useless". Of all the respondents only $12 \%$ were satisfied with the responses of the local government and three chemical plants following their complaints. 
Table 5

Supervision actions of the local governments and its agencies on KD.

\begin{tabular}{|c|c|c|}
\hline Level & Agency $^{\mathrm{a}}$ & Supervision measures and actions \\
\hline \multirow[t]{8}{*}{ Hebei Province } & HIITD & $\begin{array}{l}\text { - General supervision of SMEs in province } \\
\text { - Granting production permits to new pesticide plants } \\
\text { - Annually checking of adequacy of production permits of three KD plants } \\
\text { - Promulgation of provincial environmental rules and policies } \\
\text { - Supervision pollution prevention and control of national key polluters in the province, including HY and LH } \\
\text { - Investigation of HY and LH on illegal construction of two new projects without approval; identified it as one of } \\
\text { ten key accidents of Hebei Province in } 2005 \\
\text { - Directing cleaner production measures of key enterprises, including KD } \\
\text { - Carry out environmental performance assessment on three enterprises in } 2009 \\
\text { - Conducted environmental inspection in } 2009 \text { and found illegally discharge of pollution in all three plants } \\
\text { - Announced illegal activities and punishment of KD } \\
\text { - Put three KD plants on the provincial list of key enterprises } \\
\text { - Strengthened supervision and examination on the dangerous wastes of KD since } 2011 \\
\text { - Conducted pollution sources survey from } 2007 \text { to } 2009 \text { (with HDA and HBS) }\end{array}$ \\
\hline & HAWS & - Guided and supervised the safety management of ZJK and Jasmine AWS \\
\hline & $\mathrm{HBH}$ & - Strengthened supervision and examination on dangerous wastes of KD since 2011 \\
\hline & HDA & $\begin{array}{l}\text { - Examined and approved new pesticide products of KD } \\
\text { - Conducted pollution sources survey from } 2007 \text { to } 2009 \text { (with EPB and HBS) }\end{array}$ \\
\hline & HAQTS & - Supervised the pressure vessels management of KD \\
\hline & HEIQB & - Supervised the quality of the KD products \\
\hline & SCD & - Supervised the export of the KD products \\
\hline & HBS & $\begin{array}{l}\text { - Conducted the pollution sources survey from } 2007 \text { to } 2009 \text { (with EPB and HDA) } \\
\text { - Environmental statistics of key enterprises }\end{array}$ \\
\hline \multirow[t]{3}{*}{ ZJK city } & ZEPB & $\begin{array}{l}\text { - Promulgated the prefectural environmental notices } \\
\text { - Supervised pollution prevention and control of the national and prefectural key polluters, including three KD plants } \\
\text { - Performed regular monitoring on surface water, groundwater, air and noise of three plants } \\
\text { - Monitored the wastewater and dangerous waste discharge } \\
\text { - Investigated HY and LH on illegal construction of two new projects without approval in } 2005 \\
\text { - Generated and disclosed annual report on dangerous wastes of the three plants via its website since } 2011 \\
\text { - Published regularly online monitoring data on the local environmental quality and pollutants discharges from three plants } \\
\text { - Conducted assessment on the emission reduction and environmental targets achievement of LH and HY in } 2011\end{array}$ \\
\hline & ZAWS & $\begin{array}{l}\text { - Included the three plants in the } 1 \text { st list for making production safety emergency plan in } 2012 \\
\text { - Steered the work safety management of JASW }\end{array}$ \\
\hline & ZBIIT & - General supervision SMEs in city \\
\hline \multirow[t]{11}{*}{ Jasmine county } & JCG & $\begin{array}{l}\text { - Decision to exclude chemical industry as priority sector in the 12th FYP in } 2011 \\
\text { - Ordered LH to stop production and compensate } 687 \text { farmer households after chemical leak in } 2003\end{array}$ \\
\hline & JBDR & $\begin{array}{l}\text { - Developed the local FYP and industrial measures } \\
\text { - Helped the KD to get the national environmental subsidies }\end{array}$ \\
\hline & JBIIT & $\begin{array}{l}\text { - Monitored and guided the SMEs in county } \\
\text { - Preliminarily annual check of production permits of three plants }\end{array}$ \\
\hline & JBA & - Preliminarily check on application of new pesticide production of KD \\
\hline & JEPB & $\begin{array}{l}\text { - Supervision of pollution prevention and control of three plants } \\
\text { - Imposed fine on LH after a chemical accident in } 2003 \\
\text { - Conducted administrative penalties ( } 200,000 \text { Yuan for each plant) for illegal construction of two new projects without } \\
\text { approval in HY and LH in } 2005 \\
\text { - Required the three plants to conduct environmental impact assessments (EIAs) in } 2010 \text { and } 2011 \\
\text { - Listed three plants as high risk enterprises } \\
\text { - Conducted frequent environmental inspections on three plants ( } 2-3 \text { times per month) } \\
\text { - Monitored the operation of environmental facilities in three plants } \\
\text { - Implemented the comprehensive screenings on the dangerous chemicals, potential safety problems, water pollution, } \\
\text { - and illegal pollution emissions } \\
\text { - Took five measures to strengthen the dangerous wastes management of three plants in } 2011\end{array}$ \\
\hline & JAWS & $\begin{array}{l}\text { - Listed three plants as high risk enterprises } \\
\text { - Surveilled work and hazardous chemical safety in three plants } \\
\text { - Conducted regular inspections on three plants ( } 1-2 \text { times per month) } \\
\text { - Checked transportation safety of the dangerous chemicals in three plants in } 2010 \\
\text { - Conducted "Work Safety Year" campaign to prevent illegal operations and accidents in } 2011 \\
\text { - Conducted special safety inspection on dangerous chemicals and chemical enterprises in } 2012\end{array}$ \\
\hline & JAQTS & - Conducted (quarterly) production facilities inspection on the three plants \\
\hline & $\mathrm{JBH}$ & $\begin{array}{l}\text { - Supervised dangerous waste management of three plants } \\
\text { - Inspected occupational health of the three plants }\end{array}$ \\
\hline & JBPS & - Conducted fire protection on three plants (every half year) \\
\hline & JBS & - Conducted economic and environmental statistics of local SMEs \\
\hline & JBTT & - Checked transportation safety of the dangerous chemicals in three plants in 2010 \\
\hline
\end{tabular}

${ }^{\mathrm{a}}$ HIITD, Hebei Industry and Information Technology Department; HEPB, Hebei Environmental Protection Bureau; HAWS, Hepei Administration of Work Safety; HBH, Hebei

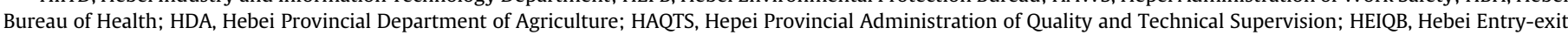

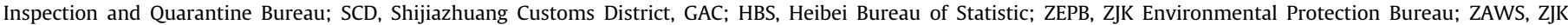

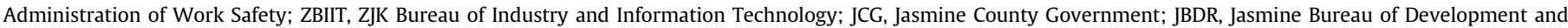

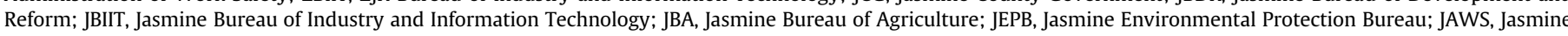

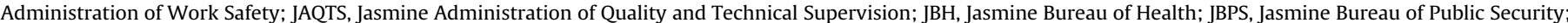
JBS, Jasmine Bureau of Statistics; JBTT, Jasmine Bureau of Traffic and Transport. 


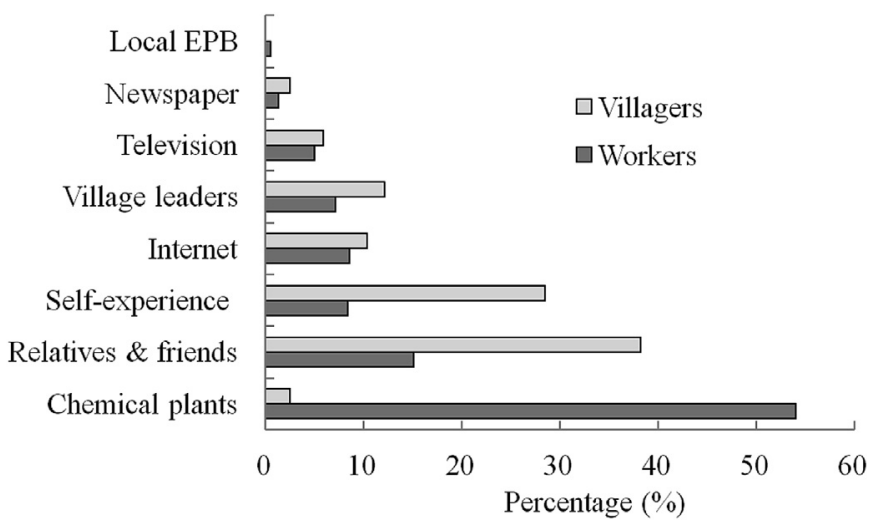

Fig. 4. Sources of information on the chemical plants for the workers and non-workers $(n=523)$.

Although other studies hypothesized and found that local residents and polluter victims aligned with the media to mitigate and prevent irresponsible and polluting behavior of SMEs by naming and shaming wrongdoing and celebrating best practices (Klein, 2011; Mol, 2009; Tang and Tang, 2012; Yang and Calhoun, 2007), no major visible media influence was found in this case. A national and local media search on Internet found only ten media messages reporting on environmental pollution of KD from 2007 to 2011. Two reports were from official sources (China Environmental News organized by MEP, and the provincial TV program "Green Home"), and the other eight media reports included blogs, Internet Fora, internet discussion groups, bulletin board systems (BBS), and an NGO website. For example, on 17 July 2008, one Netizen posted a piece of news on drinking water pollution and human health impacts of LH on a Chinese BBS-provider Baidu Tieba. Twenty four people followed it including two journalists, one researcher, one student and several local citizens nearby the plants. According to our interviews, two to four journalists have been invited by this Netizen to investigate and report on the local environmental pollution, but were stopped by the local government. In addition, no environmental NGOs could be detected that campaigned on the KD factories and/or had an impact in improving the local situation. Obviously, local residents lacked communication strategies and skills to work with media. NGO involvement in such a sensitive issue at the local level was also very limited.

\section{International value chains}

While for larger Chinese companies motivations and commitments of company managers often play an important role in the adoption of environmental performance measures (Darnall et al.,

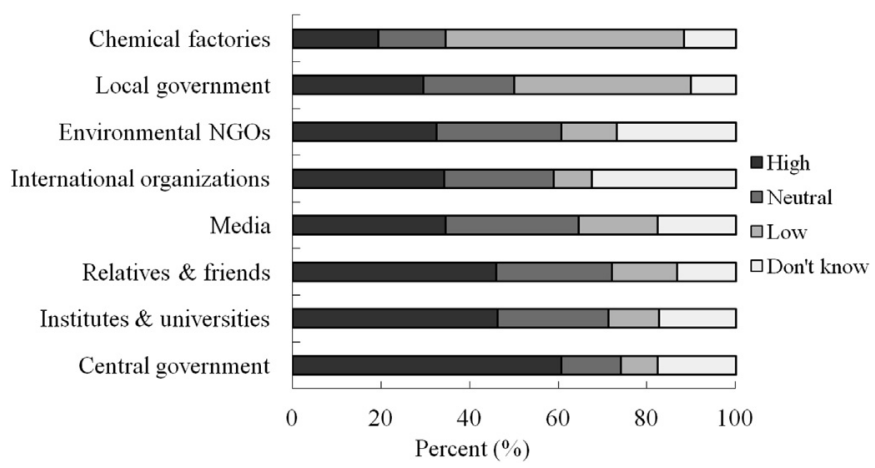

Fig. 5. Level of trust in the different information sources as perceived by the respondents $(n=523)$.
2009; Zadek et al., 2012), this is often not the case in SMEs. According to interviews with the environmental managers of the three plants, top level managers and value chain pressures-rather than plant managers from the three plants-recognized the importance of corporate social and environmental responsibility and pushed for the introduction of environmental management systems. The parent company of KD required the plants to establish environmental and health management systems to prevent and control environmental pollution. As suppliers of multi-national corporations such as BASF and Makhteshim Agan Industries Ltd, the plants did feel increasing pressures from overseas clients. International buyers requested not just product quality but also better environmental management and performance of the three plants.

In recent years internal documents on production safety, occupational health and environment have been formulated in all three plants. They have established environmental management systems (EMS), safety management systems (SMS), and environmental emergency plans. HY obtained voluntary certifications such as ISO 9000 , ISO 14000, and OHSAS 18001. XY obtained ISO 9000 certification. In 2013 LH was in the process for obtaining ISO 9000, ISO 14000 , and OHSAS 18001 certifications. In each of the plants one of the deputy managers was in charge of environmental and work safety management. Ad hoc environmental and safety offices were established and were staffed with 2 or 3 fulltime staff and 5 or 6 part-time production line workers. The interviewed managers acknowledged that they were not yet ready to produce annual environmental report and to disclose such reports to the public. Persisting environmental problems were blamed on internal factors: low awareness of the top management, limited environmental budget and a lack of environmental staff and skills. This indicated that enabling measures should be provided by the government to build capacities of SMEs in this regard, such as access to bank loans, environmental training, and information exchange among chemical SMEs.

\section{Conclusion}

All signs indicate that the national governmental authorities in Beijing are fully aware of the seriousness of China's deplorable state of the environment. Over the past years environmental protection and improvements have emerged high on the political agenda in Beijing, as evidenced by the 12th Five Year Plan (2011-2015), the many new environmental initiatives taken by the government (e.g. on developing environmental insurances, opening up environmental information for the public, developing plans for low carbon society, and major investments in renewable energy), and proclaimed priority of ecological civilization by the new leadership. But it is also widely reported that these national plans and ideas meet structural barriers, difficulties and obstructions in their local implementation (Kostka and Mol, 2013).

This case study on KD chemical factories in Jasmine county, Hebei province, illustrated that the ecological modernization of small and medium-sized chemical industries in rural China indeed falls victim to implementation controversies. While national plans and policies are all set for the environmental upgrading of polluting chemical SMEs, and mounting pressures by civil society and through international value chains support such transition, the implementation of these plans and policies by local governments and their EPBs largely stuck in the mud. The lists of tasks and responsibilities of local EPBs and governments are paralleled by numerous implementation failures: the EIA was not implemented timely, illegal dumpings were not stopped, waste treatment technologies were installed at a very late moment, monitoring failed to include toxic components, and accidents continued to occur. Our 
What is the likelyhood that you will (re)locate far away from the chemical plant?

How do you consider the risks of the chemical plant?

How is your attitude towards building a chemical plant nearby your village?
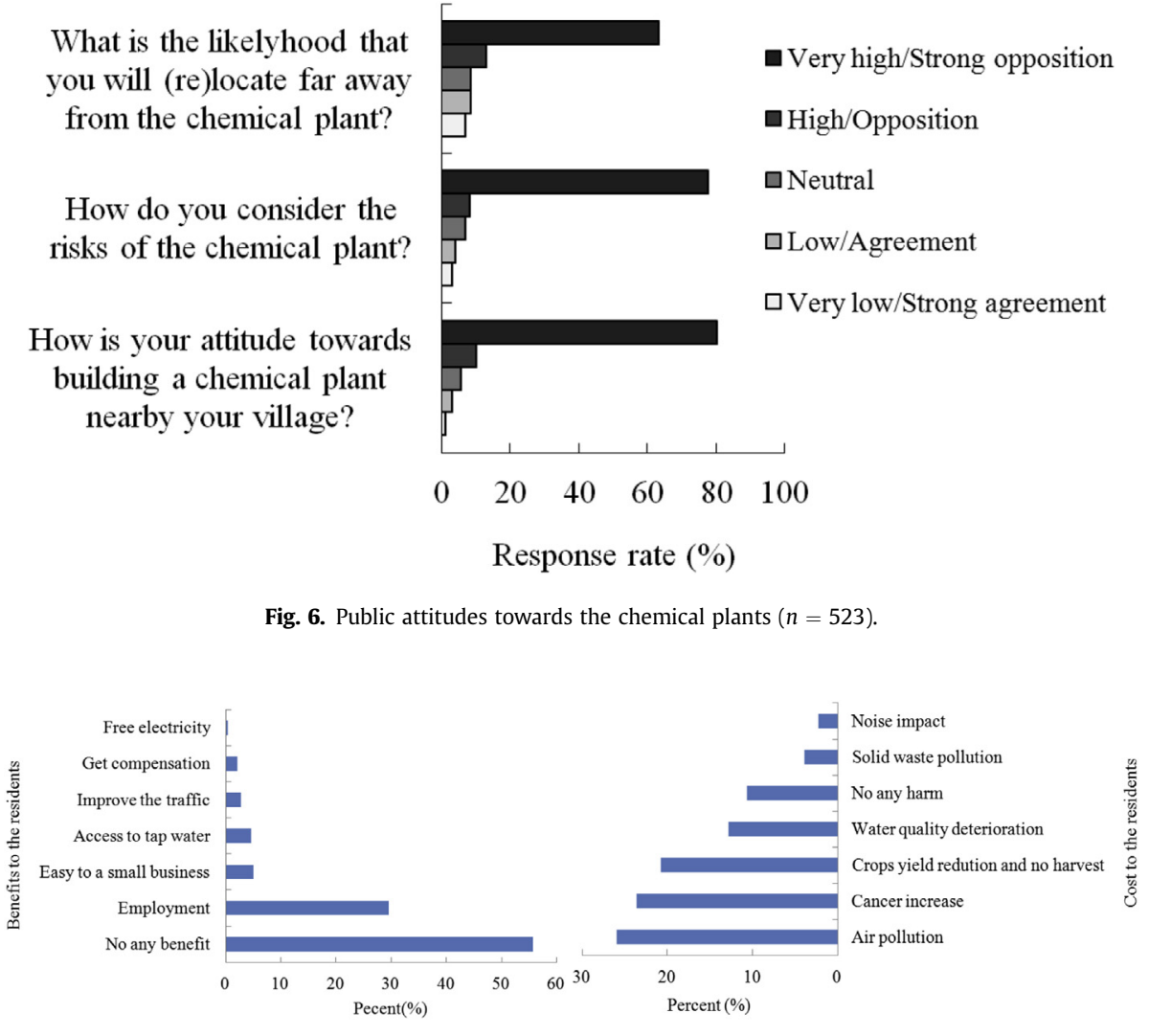

Fig. 7. Perceived benefits and costs of the chemical plants by the respondents $(n=523)$.
Very high/Strong opposition

High/Opposition

aNeutral

口Low/Agreement

$\square$ Very low/Strong agreement ds the chemical plants $(n=523)$. case study provides evidence that parallel (economic) interests of and intricate ties and collaboration between the local government and local industry management enabled the companies to continue business as usual. Besides that, rural communities proved unable to collectively raise their voice and (media) visibility to press polluting firms towards improvements.

Still, there are also hopeful signs in rural China. The ownership of local plants is increasingly put at a distance from local leaders, and the local government-SMEs alliance has started to lose its power following increasing interventions from the national government on local governments. In line with the shift of China's position in the world economy, local leaders have gradually changed economic priorities towards less polluting and more 'value-added' and knowledge intensive sectors (as we saw in our case study). And various developments and policy initiatives - e.g. for local democracy and participation, open information, and media reporting - may enhance the civil society powers by the inability of local leaders to neglect environmental accountability, transparency and legitimacy. But still this all will most likely be an uphill battle in rural China.

\section{Acknowledgments}

This research was financed primarily by the National Natural Science Foundation of China (71103175 and 41171394), International Science \& Technology Cooperation Program of China (2012DFA91150), Ministry of Education of China (NCET10-0806), Key Project of the Chinese Academy of Sciences under Grant No. KZZD-EW-TZ-12, Netherlands Royal Academy of Arts and Sciences (KNAW) and the Chinese Academy of Sciences (11CDP028), and the SURE project (Netherlands Royal Academy of Arts and Sciences and MoST). Thanks to the reviewers for their comments. We thank Yueqing Zhang, Lin Wang and others for their work on data collection and input of the questionnaires. The participation of respondents in interviews and in the survey is greatly appreciated.

\section{References}

Darnall, N., Henriques, I., Sadorsky, P., 2009. Adopting proactive environmental strategy: the influence of stakeholders and firm size. J. Manag. Stud. 47 (6), 1072-1094.

Dong, F.Y., 2012. Public Role Vital in Building Green Society. China Daily, 15 December. Available at: http://www.chinadaily.com.cn/bizchina/greenchina/ 2012-12/15/content_16026525.htm (accessed 15.06.13.).

Göbel, C., Ong, L.H., 2012. Social Unrest in China. Europe China Research and Advice Network.

Grasa, G., Navarro, V., Rubio, O., Peña, J.A., Santamaria, J., 2002. A comparative study of risk perception in small and large communities where chemical industries are present. J. Loss Prev. Process Ind. 15 (6), 525-530.

Guo, Z.Y., Zheng, Z.S., 2012. Local government, polluting enterprise and environmental pollution: based on MATLAB software. J. Softw. 7 (10), 2182-2188.

He, Q.S., Yang, Y.Y., 2012. Effect of EU environmental directives on chemical industries in Zhejiang. Chem. Ind. Time 24 (7), 75-77 (in Chinese).

He, G.Z., Zhang, L., Lu, Y.L., Mol, A.P.J., 2011. Managing major chemical accidents in China: towards effective risk information. J. Hazard. Mater. 187, 171-181.

He, G.Z., Lu, Y.L., Mol, A.P.J., Beckers, T., 2012a. Changes and challenges: China's environmental management in transition. Environ. Dev. 3, 25-38.

He, G.Z., Mol, A.P.J., Lu, Y.L., 2012b. Trust and credibility in governing China's risk society. Environ. Sci. Technol. 46 (14), 7442-7443.

Henriques, I., Sadorsky, P., 1999. The relationship between environmental commitment and managerial perceptions of stakeholder importance. Acad. Manag. J. 42, 87-99.

Huang, L., Ban, J., Sun, K. Han, Y.T., Yuan, Z.W., Bi, J., 2013. The influence of public perception on risk acceptance of the chemical industry and the assistance for risk communication. Saf. Sci. 51 (1), 232-240.

Kennedy, J., October 29th, 2012. Environmental protests in China on dramatic rise South China Morning Post. Available at: http://www.scmp.com/news/china/ article/1072407/environmental-protests-china-rise-expert-says (accessed 14.06.13.).

Klein, L.W., 2011. Political Consequences of the Rise of the Internet: Political Beliefs and Practices of Chinese Netizens. Journalist Resource Advance Online Publication, October 13th. Available at: http://journalistsresource.org/studies/ society/internet/chinese-netizens-political-beliefs (accessed 14.06.13.). 
Kostka, G., 2013. Environmental protection bureau leadership at the provincial level in China: examining diverging career backgrounds and appointment patterns. J. Environ. Policy Plann. 15 (1), 41-63.

Kostka, G., Mol, A.P.J., 2013. Implementation and participation in China's loca environmental politics: challenges and innovations. J. Environ. Policy Plann. 15 (1), 3-16.

Lee, S.Y., 2008. Drivers for the participation of small and medium-sized suppliers in green supply chain initiatives. Supply Chain Manag. 13 (3), 185-198.

Liu, X.B., Wang, C., Shishime, T., Fujitsuka, T., 2010. Environmental activisms of firm's neighboring residents: an empirical study in China. J. Clean. Prod. 18 1001-1008.

Liu, L., Zheng, B., Bi, J., 2012. Reforming China's multi-level environmental governance: lessons from the 11th five-year plan. Environ. Sci. Policy 21, 106-111.

Lu, Y.L., Giesy, J.P., Holliday, L., 2007. Implementing the Stockholm Convention on Persistent Organic Pollutants. The National Academies Press, Washington D.C.

McElwee, C.R., 2011. Environmental Law in China. Oxford University Press, Oxford.

MEP, 2012. Guide for National Survey on Chemicals Production and Environment. MEP Document No. 155. Ministry of Environmental Protection of China (in Chinese).

MEP, 2013. The 12th FYP for the prevention and control of chemical environmental risks. MEP Document No. 20. Ministry of Environmental Protection of China (in Chinese).

Mol, A.P.J., 2009. Environmental governance through information: China and Vietnam. Singapore J. Trop. Geogr. 30 (1), 114-129.

Mol, A.P.J., 2011. China's ascent and Africa's environment. Glob. Environ. Chang. 21 (3), 785-794.

Mol, A.P.J., Carter, N.T., 2006. China's environmental governance in transition. Environ. Polit. 15 (2), 149-170.

National Bureau of Statistics of China, 2011. China Statistical Yearbook 2011. China Statistics Press, Beijing (in Chinese).

OCED, 2006. Environmental Compliance and Enforcement in China: an Assessment of Current Practices and Ways Forward. Asian Environmental Compliance and Enforcement Network Report. OECD.

Qi, G., Zeng, S., Tam, C., Yin, H., Zou, H., 2012. Stakeholders' influences on corporate green innovation strategy: a case study of manufacturing firms in China. Corp. Soc. Responsib. Environ. Manag. 20 (1), 1-14.

Smallbone, D., Welter, F., 2001. The role of government in SME development in transition economies. Int. Small Bus. J. 19 (4), 63-77.
Stevens, R.J.L., Moustapha, M.M., Evelyn, P., Stevenson, R.J., 2013. Analysis of the emerging China green era and its influence on small and medium-sized enterprises development. J. Sustain. Dev. 6 (4), 86-105.

Sun, Y.F., 2009. Geographical Distribution of "Cancer Villages" in China (Bachlor dissertation). Geographical Department, Central China Normal University, Wuhan.

Tang, Z., Tang, J.T., 2012. Stakeholder-firm power difference, stakeholders' CSR orientation, and SMEs' environmental performance in China. J. Bus. Ventur. 27 (4), 436-450.

Van Rooij, B., Lo, C.W.H., 2010. Fragile convergence: understanding variation in the enforcement of China's industrial pollution law. L. Policy 32, 14-37.

Wang, T.Y., Lv, Y.L., Zhang, H., Shi, Y.J., 2005. Contamination of persistent organic pollutants and relevant management in China. Environ. Int. 31 (6), 813-821.

Wang, M., Webber, M., Finlayson, B., Barnett, J., 2008. Rural industries and water pollution in China. J. Environ. Manag. 86 (4), 648-659.

Wang, H., Yan, Z.G., Li, H., 2012. Progress of environmental management and risk assessment of industrial chemicals in China. Environ. Pollut. 165, 174-181.

Weng, M.H., Lin, C.Y., 2011. Determinants of green innovation adoption for small and medium-size enterprises (SMES). Afr. J. Bus. Manag. 5 (22), 9154-9163.

Wu, W. Leung, A., 2005. Does a micro-macro link exist between managerial value of reciprocity, social capital and firm performance? the case of SMEs in China. Asia Pac. J. Manag. 22, 445-463.

Xinhua, 2012. Chinese Ministries Give SMEs Preferential Policies. Available at: http://news.xinhuanet.com/english/china/2012-01/06/c_122548702.htm (accessed 13.06.13.).

Xu, H.G., Liu, D.Z., Wu, H.Z., 2001. Environmental regionalization for the management of township and village enterprises in China. J. Environ. Manag. 63, 203-210.

Yang, G., Calhoun, C., July 19th, 2007. Media, Civil Society, and the Rise of a Green Public Sphere in China. SAGE. Available at: http://cin.sagepub.com/content/21/ 2/211.abstract (accessed 13.06.13.)

Zadek, S., Forstater, M., Yu, K., 2012. Corporate Responsibility and Sustainable Economic Development in China: Implications for Business. U.S. Chamber of Commerce Research Report.

Zhang, L., 2002. Ecologizing Industrialization in Chinese Small Towns (Ph. D thesis). Wageningen University Publication, Wageningen.

Zhang, L., He, G.Z., Mol, A.P.J., Lu, Y.L., 2013. Public perceptions of environmental risk in China. J. Risk Res. 16 (2), 195-209. 